\title{
Further support for the role of heroism in human mate choice
}

Manpal Singh Bhogal (ORCID: 0000-0002-7913-0726)*(m.s.b2@wlv.ac.uk)1

$\&$

James E Bartlett (ORCID: 0000-0002-4191-5245) (jbartlett@arden.ac.uk)2

1 Department of Psychology, Evolution and Human Behaviour Research Group, University of Wolverhampton, WV1 1LY, UK

${ }_{2}$ School of Psychology, Arden University, Coventry, CV3 4FJ, UK

*corresponding author

Word count: 2500 (all inclusive) 
Acknowledgments: We thank Daniel Farrelly and Benedict Jones for their valuable comments on an earlier draft of this manuscript. We thank Aniqah Akhtar, Eniola Balogun, Marwa Hakami, Hannah Sanghera, Hayley Soloman, and Kosar Yaghoubi for collecting part of the data for this study. We also thank Catherine Salmon for handling our manuscript and the two anonymous reviewers for their time and valuable comments throughout the peer review process.

Author contributions: MSB formulated the project, designed the experiment and collected the data. JB conducted all analyses. MSB and JB wrote the article.

Financial support: This research received no specific funding grant from any funding agency, commercial or not-for-profit sectors.

Conflict of interest: Authors declare no conflict of interest.

Research transparency and reproducibility: Sample size has been considered using a power analysis. Preregistered hypotheses, materials, raw data, and reproducible analyses are available on the Open Science Framework: https://osf.io/qbzw7/ 


\begin{abstract}
Although evidence suggests that altruistic behavior can act as a mating signal, little research has explored the role of heroism in mate choice. Previous research has focused on women only, ignoring the role of heroism in male mate choice. Here, we extended and replicated previous research on the role of heroism in human mate choice. Participants $(N=276)$ rated how desirable targets were for a short-term and long-term relationship, which varied in heroism. The findings showed men and women reported higher desirability for heroic targets for long-term compared to short-term relationships, although this pattern was more prominent in women. These findings add support to the role of heroism in mate choice by exploring the role of heroism in male and female mate choice.
\end{abstract}

Keywords: attraction; heroism; romantic relationships; prosociality; mutual mate choice

Pubic significance statement: Heterosexual men and women find potential partners who behave heroically more attractive compared to those who behave non-heroically. This attraction is important when seeking a long-term compared to a short-term relationship, as long-term relationships require good partner/parental qualities. 
Heroism is defined as a form of altruistic behavior involving personal risk, which can often involve acts which are life-threatening (Margana et al. 2019). When viewing heroism through the handicap principle (Zahavi, 1975), heroism can be an adaptive trait in mate choice due to its costly nature (the risks and energy exerted through the display of heroic acts). Through displaying heroism, one can signal that they can bear the costs of behaving heroically, making them desirable in mate choice contexts.

Where several studies have shown that altruism is important in mate choice (see Bhogal et al. 2019 for a review), the limited, yet informative literature on the role of heroism in mate choice shows that women find heroic targets to be desirable, particularly for long-term relationships (Kelly \& Dunbar, 2001; Margana et al. 2019), as heroism signals good partner and parental qualities (Farrelly, 2011; Kokko, 1998; Margana et al., 2019). Furthermore, when presented with fictional characters, women are attracted to heroic men who display bravery (Kruger et al. 2003; Rusch et al. 2015).

Previous literature exploring the role of heroism in human mate choice has largely focused on female mate choice. This could be due to the fact that the most research finds that women are attracted to men who display benefit provisioning behavior (see Bhogal et al., 2020; Bhogal et al., 2019; Farrelly et al., 2007; Phillips et al. 2008). However, there is some (although limited) research showing that men are attracted to women who display benefit provisioning behavior (although this effect is generally more prominent in women than men, see Bhogal et al. 2019; Farrelly \& King, 2019). However, due to the majority of research showing the importance of heroism in female mate choice, we expected women to find heroism more desirable than men. We aimed to conceptually replicate and extend the findings of Margana et al. (2019). 
Hypotheses

The following hypotheses were pre-registered on the Open Science Framework (OSF) (https://osf.io/qbzw7/):

H1: Participants would find heroic targets as more desirable than neutral and low heroic targets.

$\mathrm{H} 2$ : Women would report high heroic targets to be more desirable than men.

H3: Heroic targets will be more attractive for a long-term compared to a short-term relationship (a). This will interact with the participants' sex, with women finding heroic men more attractive for long-term, compared to short-term relationships (b).

\section{Method}

Participants and design

To guide our anticipated sample size, an a priori power analysis was conducted using G*Power (Faul et al. 2009). To achieve $80 \%$ power (ANOVA: Repeated measures, between factors; .05 alpha; .15 effect size; 2 groups; 12 measurements; .5 correlation), G*Power recommended at least 192 participants. The sample consisted of 276 heterosexual members of the general public across the UK (101 men, 175 women, Mage=25.89 years old, $S D=8.49)$. Participants completed the study anonymously online via Qualtrics, or in person using paper/pen.

We adopted a 3 (within-subjects factor: heroism-low/control/high) x 2 (betweensubjects factor: participants' sex-men/women) x 2 (within-subjects factor: relationship typeshort-term/long-term) mixed design. The dependent variable (DV) was the mean desirability rating towards the target in the scenario (a Likert scale of $1=$ very undesirable to $5=$ very desirable, consistent with Margana et al. 2019). 
Materials and procedure

Six scenarios were used, derived from Margana et al. (2019), including two scenarios depicting a target high in heroism, two scenarios depicting a target low in heroism, and two control scenarios which were unrelated to heroism. Control scenarios were included to provide an anchor for the direction of the effects in high and low heroism. All pronouns were altered to make them gender neutral. Although all scenarios are included as supplementary material, here is an example of a target high in heroism:

"A determined and brave hiking group were ascending up the world's tallest mountain, Mount Everest, which has an altitude of 8,848m high. Climbing these heights can be challenging for any level of hiker. The group did well, overcoming all of the obstacles, almost making it to the top, when a member started to struggle, showing signs of becoming weak. Person A noticed their hiking partner struggling to climb and decided to stop and help them. Stopping at such high altitudes can be dangerous as there is such little oxygen and a potential for the body to freeze from the cold. However, Person A was determined to make sure they all made it to the top of the mountain."

Participants were firstly presented with definitions regarding relationship types (shortterm relationship/long-term relationship). These definitions were taken from previous research (Farrelly et al. 2016). Participants then read each scenario before rating how desirable the target was in each scenario for a short-term relationship and a long-term relationship (consistent with previous research, e.g. Kelly \& Dunbar, 2001; Margana et al. 2019). Participants completed all scenarios, and these were presented in a randomized order. This study was approved by the psychology department at the host university. 


\section{Results}

The analyses were performed in R (R Core Team, 2019) and JASP (2018). Data and reproducible analyses are available on the OSF (https://osf.io/qbzw7/). To control for an increase in type I errors due to multiplicity, the $p$ values in the ANOVA were adjusted using the Holm correction (Holm, 1979; see Cramer et al. 2016). Effects that violated sphericity were adjusted using the Greenhouse-Geisser correction.

There was a significant main effect of sex, $F(1,274)=148.23, p<.001, \omega 2=.35$, heroism, $F(1.87,511.82)=168.96, p<.001, \omega 2=.19$, and relationship type, $F(1,274)=6.52, p=.022$, $\omega 2=.002$. Heroism was explored to address hypothesis one. Participants reported higher desirability ratings for high heroism than control (mean difference $=0.45, p<.001$ ) and low heroism (mean difference $=1.00, p<.001$ ). Participants reported a higher desirability rating for control than low heroism (mean difference $=0.54, p<.001$ ).

There was a significant interaction between sex and heroism, $F(1.87,511.82)=28.56$, $p<.001, \omega_{2}=.04$, and relationship type and heroism, $F(1.60,439.24)=16.43, p<.001, \omega_{2}=.007$, but not between sex and relationship type, $F(1,274)=1.99, p=.16, \omega_{2}<.001$. In order to address hypothesis two, the interaction between sex and heroism was explored by comparing men and women for each heroism condition (Holm corrected). Women reported higher desirability ratings than men for high heroism (mean difference $=0.75, p^{<.001)}$, control (mean difference $=1.41, p<001$ ), and low heroism (mean difference $=0.66, p<.001$ ). Consistent with hypothesis two, this shows that women consistently reported higher desirability ratings for heroic targets than men.

There was a significant three-way interaction, $F(1.60,439.24)=6.26, p=.013, \omega 2=.003$. The interaction is displayed graphically in Figure 1. In order to address hypothesis three, four comparisons were performed focusing on the high heroism condition (Holm corrected). The 
difference in desirability ratings was compared between short- and long-term relationship for each sex. Then, the difference in ratings was compared between sexes for each relationship type. Women reported higher desirability ratings for high heroic targets for long-term relationships than short-term relationships (mean difference $=0.20, p=.002$ ). Men also reported higher desirability ratings for high heroic targets for long-term relationships than short-term relationships (mean difference $=0.26, p=.003$ ). When comparing sexes, women reported higher desirability ratings than men for high heroic targets for long-term relationships (mean difference $=0.72, p<.001)$. Women also reported higher desirability ratings than men for high heroic targets for short-term relationships (mean difference $=0.78, p<.001$ ).

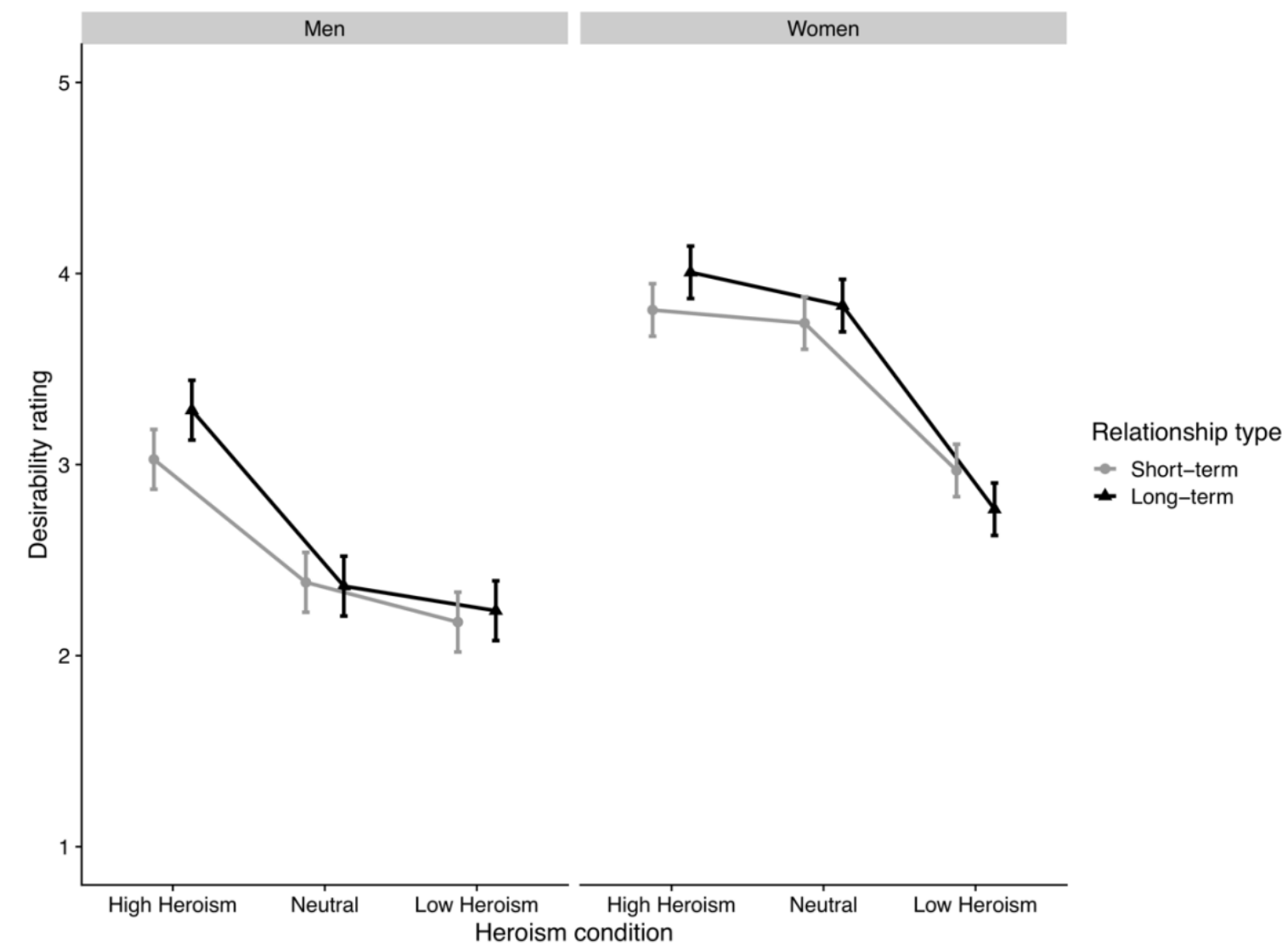

Figure 1. The interaction between heroism and relationship type separated by sex. The error bars represent $95 \%$ confidence intervals. 
Table 1: Mean (SD) desirability by sex, heroism, and relationship type.

\begin{tabular}{|c|c|c|c|c|}
\hline Heroism & Relationship type & Sex & Mean & $S D$ \\
\hline \multirow[t]{4}{*}{ Low } & Short-term & Male & 2.05 & 0.86 \\
\hline & & Female & 2.84 & 0.80 \\
\hline & Long-term & Male & 2.11 & 0.88 \\
\hline & & Female & 2.64 & 0.81 \\
\hline \multirow[t]{4}{*}{ Control } & Short-term & Male & 2.26 & 1.19 \\
\hline & & Female & 3.61 & 0.64 \\
\hline & Long-term & Male & 2.24 & 1.19 \\
\hline & & Female & 3.71 & 0.63 \\
\hline \multirow[t]{4}{*}{ High } & Short-term & Male & 2.90 & 0.98 \\
\hline & & Female & 3.68 & 0.81 \\
\hline & Long-term & Male & 3.16 & 0.93 \\
\hline & & Female & 3.88 & 0.79 \\
\hline
\end{tabular}




\section{Discussion}

The aim of this study was to 1) further explore and extend the role of heroism and mate choice and 2) to explore the role of heroism in men and women's mate choice. Hypothesis one was supported, as high heroic targets were rated as more desirable than low-heroic targets. Control scenarios were included to anchor the results, as desirability ratings for high heroic targets were higher than desirability ratings for the control condition, and desirability ratings for low heroic targets were lower than desirability ratings for the control condition. Hypothesis two was supported, as women rated heroic targets as more desirable than men. Hypothesis three was explored in two stages. Part (a) was supported as both men and women reported higher desirability ratings for high heroic targets in long-term than short-term relationships. Part (b) was also supported as this effect interacted with the participants' sex. Women reported higher desirability ratings for high heroic targets than men for both short-term and long-term relationships. The effect sizes were larger in the comparison between men and women than the within-subject comparisons between short-term and long-term relationships. As a result, the findings of this study lend support for the role of mutual mate choice in the desirability of heroism, but the effect is more pronounced in women than men.

Our findings replicate the limited literature showing the important role of heroism in human mate choice (Bassett \& Moss, 2004; Margana et al. 2019; Kelly \& Dunbar, 2001). Furthermore, our findings are consistent with the literature showing that benefit provisioning behaviors are important for long-term compared to short-term relationships (Bhogal et al. 2019).

Due to the importance of replication in psychology (Earp \& Trafimow, 2015), we believe the findings of this study are important in the field, as this paper provides evidence that heroism is important in mate choice, where we have replicated and extended the limited research in the area on heroism and mate choice. 
Although there are strengths to this study, there are limitations in relation to the scenarios used. The scenarios used from Margana et al. (2019) included targets who are displaying extreme forms of heroism, as opposed to subtle forms of heroism. For example, one scenario displaying high heroism related to a rescue attempt whilst climbing Mount Everest, and one of the scenarios depicting low heroism was related to the Ebola outbreak with both scenarios involving an extreme risk of personal injury. Future research could include more subtle, realistic scenarios which we may encounter in our day to day lives. In addition, future research could explore a variety of characteristics and their relation to heroism, such as how status influences heroic behaviour (see Lyons, 2005).

In summary, our findings extend and replicate previous literature on the role of heroism in mate choice. These findings replicate the results of Margana et al. (2019), but also extend the literature on heroism and mate choice by taking male mate choice into account. The findings here show that men and women find heroism to be a desirable trait in long-term partners, yet consistent with previous literature, these findings show that women find heroism to be a more desirable trait than men.

\section{References}

Bassett, J. F., \& Moss, B. (2004). Men and women prefer risk takers as romantic and nonromantic partners. Current Research in Social Psychology, 9(10), 1-10.

Bhogal, M. S., Galbraith, N., \& Manktelow, K. (2019). A Research Note on the Influence of Relationship Length and Sex on Preferences for Altruistic and Cooperative Mates. Psychological Reports, 122(2), 550-557. https://doi.org/10.1177/0033294118764640

Bhogal, M. S, Bartlett, J. E., \& Farrelly, D. (2019). The influence of mate choice motivation on non-financial altruism. Current Psychology, 38(4), 959-964. https://doi.org/10.1007/s12144-018-0070-x 
Bhogal, M. S., Farrelly, D., \& Galbraith, N. (2019). The role of prosocial behaviors in mate choice: A critical review of the literature. Current Psychology, 38(4), 1062-1075. https://doi.org/10.1007/s12144-019-00308-8

Bhogal, M. S., Farrelly, D., Galbraith, N., Manktelow, K., \& Bradley, H. (2020). The role of altruistic costs in human mate choice. Personality and Individual Differences, 160. doi.org/10.1016/j.paid.2020.109939

Cramer, A. O. J., van Ravenzwaaij, D., Matzke, D., Steingroever, H., Wetzels, R., Grasman, R. P. P. P., ... Wagenmakers, E.-J. (2016). Hidden multiplicity in exploratory multiway ANOVA: Prevalence and remedies. Psychonomic Bulletin \& Review, 23(2), 640-647. https://doi.org/10.3758/s13423-015-0913-5

Earp, B. D., \& Trafimow, D. (2015). Replication, falsification, and the crisis of confidence in social psychology. Frontiers in Psychology, 6, 1-11. https://doi.org/10.3389/fpsyg.2015.00621

Farrelly, D. (2011). Cooperation as a signal of genetic or phenotypic quality in female mate choice? Evidence from preferences across the menstrual cycle. British Journal of Psychology, 102(3), 406-430. https://doi.org/10.1348/000712610X532896

Farrelly, D., Clemson, P., \& Guthrie, M. (2016). Are women's mate preferences for altruism also influenced by physical attractiveness? Evolutionary Psychology, 14(1), 1-6.

Farrelly, D., \& King, L. (2019). Mutual mate choice drives the desirability of altruism in relationships. Current Psychology, 38(4), 977-981. https://doi.org/10.1007/s12144-01900194-0

Farrelly, D., Lazarus, J., \& Roberts, G. (2007). Altruists Attract. Evolutionary Psychology, 5(2), 313-329.

Faul, F., Erdfelder, E., Buchner, A., \& Lang, A.-G. (2009). Statistical power analyses using G*Power 3.1: Tests for correlation and regression analyses. Behavior Research 
Methods, 41(4), 1149-1160. https://doi.org/10.3758/BRM.41.4.1149

Holm, S. (1979). A Simple Sequentially Rejective Multiple Test Procedure. Scandinavian Journal of Statistics, 6(2), 65-70.

JASP Team (2018). JASP (Version 0.9) [Computer software]. Retrieved from https://jaspstats.org/.

Kelly, S., \& Dunbar, R. I. M. (2001). Who dares, wins. Human Nature, 12(2), 89-105. https://doi.org/10.1007/s12110-001-1018-6

Kokko, H. (1998). Should advertising parental care be honest? Proceedings of the Royal Society of London. Series B: Biological Sciences, 265(1408), 1871-1878. https://doi.org/10.1098/rspb.1998.0515

Kruger, D. J., Fisher, M., \& Jobling, I. (2003). Proper and dark heroes as DADS and CADS. Human Nature, 14(3), 305-317. https://doi.org/10.1007/s12110-003-1008-y

Lyons, M. (2005). Who are the heroes? Characteristics of people who rescue others. Journal of Cultural and Evolutionary Psychology, 3, 239-248

Margana, L., Bhogal, M. S., Bartlett, J. E., \& Farrelly, D. (2019). The roles of altruism, heroism, and physical attractiveness in female mate choice. Personality and Individual Differences, 137. https://doi.org/10.1016/j.paid.2018.08.018

Phillips, T., Barnard, C., Ferguson, E., \& Reader, T. (2008). Do humans prefer altruistic mates? Testing a link between sexual selection and altruism towards non-relatives. British Journal of Psychology, 99(4), 555-572. https://doi.org/10.1348/000712608X298467

R Core Team (2017). R: A language and environment for statistical computing. R Foundation for Statistical Computing, Vienna, Austria. https://www.R-project.org/.

Rusch, H., Leunissen, J. M., \& van Vugt, M. (2015). Historical and experimental evidence of 
sexual selection for war heroism. Evolution and Human Behavior, 36(5), 367-373.

https://doi.org/10.1016/J.EVOLHUMBEHAV.2015.02.005 w

Zahavi, A. (1975). Mate selection-a selection for a handicap. Journal of Theoretical Biology, $53,205-214$. 